\title{
Prognostic Value of CDX2 and Villin Expression in Advanced Stage Colorectal Carcinoma
}

\author{
Suleyman Altintas1, Mehmet Bayrak2 and Yasemin Altintas 3 \\ IDepartment of Pathology, Adana City Hospital, Adana, Turkey \\ ${ }^{2}$ Department of General Surgery / Radiology33, Adana Ortadogu Private Hospital, Adana, Turkey
}

\begin{abstract}
Objective: To determine the frequency of expression of CDX2 and Villin in a subsection of advanced stage primary colorectal cancers and detect its association with tumour differentiation, lymph node metastasis, invasion and survival.

Study Design: A descriptive study.

Place and Duration of Study: Ortadogu Private Hospital, Adana, Turkey, from January 2012 to March 2017.

Methodology: Formalin-fixed, paraffin-embedded tissue specimens were obtained from 70 patients who underwent surgery for colorectal carcinoma. Inclusion criteria were patients who underwent surgery with stage 3 and stage 4 colorectal cancer. The exclusion criteria were patients who had recurrent colorectal cancer and/or accompanying cancer in another region. Immunohistochemical technique was used for the localisation of CDX2 and Villin in colorectal cancer tissues. The catagorical variables between the groups was analysed by using the Chi-square test or Fisher Exc. test. Overall survival time was defined as the years elapsed between date of after operation and death as a result of disease (or the last follow-up date). Overall survival was analysed using the Wald test, and the log-rank test was used to examine their relationship when different parameters were applied. The survival curve was plotted using the standard Kaplan-Meier methodology. Values of $p<0.05$ were considered statistically significant.

Results: Both CDX2 and Villin had relation with gender $(p=0.045, p=0.016)$, male and female expression of CDX2 was $n=31(67.4 \%), n=15(32.6 \%)$, respectively and Villin was $n=34(68.0 \%), n=16(32.0 \%)$, respectively; age $(p=0.804, p=0.791)$, had no relation with tumor site $(p=0.131, p=0.921)$ and histologic grade $(p=0.209, p=0.579)$ and lymph node metastasis $(p=0.063, p=0.392)$ and perineural invasion $(p=0.476, p=0.053)$ and lymphovasculer invasion $(p=0.080, p=0.791)$ and overall survival $(p=0.121$, hep $=0.059)$.

Conclusion: CDX2 and Villin were not associated with any of the clinicopathologic parameters. Overall survival analysis also did not show a significant association with immunoexpression of these molecules and survival. CDX2 and Villin might not be useful as a prognostic factor in advanced stage colorectal carcinoma.
\end{abstract}

Key Words: Villin, CDX2, Colorectal carcinoma, Immunohistochemistry, Survival.

How to cite this article: Altintas S, Bayrak M, Altintas Y. Prognostic value of CDX2 and villin expression in advanced stage colorectal carcinoma. J Coll Physicians Surg Pak 2019; 29(11):1057-61.

\section{INTRODUCTION}

Colorectal carcinoma (CRC) is one of the most widespread malignant tumors worldwide. Patients who had disease at the same stage might have diverse clinical consequences due to the heterogeneity of the molecular changes.1,2 Therefore, there is a great need to understand the molecular pathology underlying CRC and to identify new biomarkers.

Caudal-type homeodomain transcription factors2 (CDX2) is a caudal-type homeobox gene, encoding a transcription factor that plays an important role in proliferation and differentiation of intestinal epithelial cells. ${ }^{3}$ Low expression of CDX2 increases susceptibility for tumors, while overexpression of CDX2 inhibits

Correspondence to: Suleyman Altintas, Adana City Hospital,

Mithat Ozsan Bulvari, Adana, Turkey

E-mail: suleymanveysmn@hotmail.com

Received: January 18, 2019; Revised: July 12, 2019;

Accepted: September 16, 2019 growth and promotes differentiation of colorectal cancer cells. ${ }^{4,5}$

Villin is a protein belonging to the gelsolin family of calcium regulated actin-binding proteins. ${ }^{6}$ Villin is a particularly specified protein and is revealed in intestinal and renal proximal tubular epithelium. Villin had been detected in $\mathrm{CRC}$ and has been used to differentiate neoplasms of intestinal origin from nonintestinal neoplasms.7,8

The rationale of this research was to clarify the importance of CDX2 and Villin expression in colorectal condition.

The objective of the study was to clarify immuno-histochemical expression of CDX2 and Villin in a subsection of advanced stage primary colorectal cancer, detect its association with tumour invasion, differentiation, survival and lymph node metastasis.

\section{METHODOLOGY}

Formalin-fixed, paraffin-embedded tissue specimens were obtained from 70 patients who underwent surgery 
for colorectal carcinoma from January 2012 to March 2017 at Ortadogu Private Hospital, Adana, Turkey. Cukurova University Clinical Ethical Board approved this study.

Inclusion criteria were patients who underwent surgery with stage 3 and stage 4 colorectal cancer. The exclusion criteria were patients who had recurrent colorectal cancer and/or accompanying cancer in another region. No chemotherapy or radiotherapy was given before operation. Clinicopathological findings such as gender, age, tumor size, tumor site, histological stage, and grade were recorded through hospital database and contact with physician, if necessary. The tumors were classified by stages with respect to the $7^{\text {th }}$ volume of the AJCC/UICC TNM classification. ${ }^{9}$ In all cases, all existing sections stained with hematoxylin and eosin were analysed. Four micrometer thick sections of the formalin-fixed and paraffin-embedded tissues were put down in poly-L-lysine-coated slides for immunohistochemistry. ${ }^{5}$

Immunohistochemical staining was performed with streptoavidin-biotin method. Briefly, the sections were de-paraffinised and incubated with $3 \%$ hydrogen peroxide for twenty minutes to block endogenous peroxidase activity. Prior to immunostaining, antigen retrieval was applied. Subsequently, slides were incubated with CDX2 (clone DAK-CDX2, dako) and Villin (clone 1D2 C3, dako) at room temperature with primary antibodies for 60 minutes. Standard avidin-biotinperoxidase complex (ABC) method was applied by employing LabVision Secondary Detection Kit (UltraVision Detection System Anti-polyvalent, HRP). AEC was applied as chromogen. Finally, the samples were sited on PBS having diaminobenzidine and $1 \%$ hydrogen

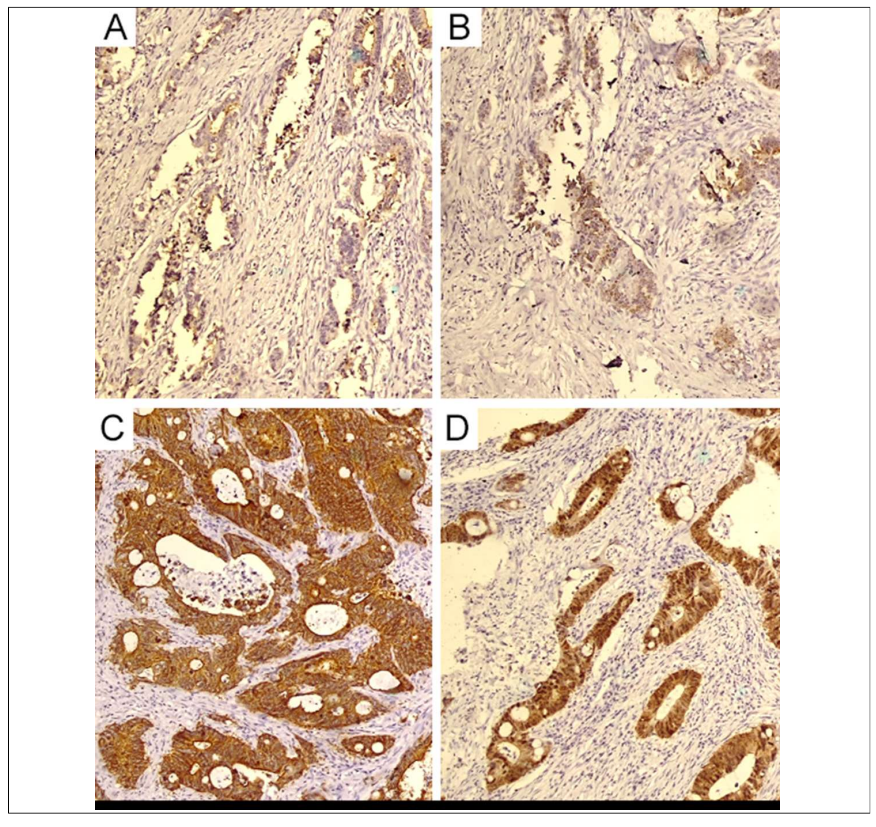

Figure 1: Representative tumours displaying: (A) villin staining, (B) focal CDX2 staining, (C) diffuse villin staining, (D) diffuse CDX2 staining. peroxide for five minutes and counterstained with hematoxylin solution for one minute and mounted.

A tumor was recorded positive, if greater than $5 \%$ of the tumor cells exhibited nuclear staining for CDX2 and apical membranous and/or cytoplasmic staining for Villin. ${ }^{5}$

The percentage of positive cells was scored in a semiquantitative method according to the following scheme: 0 (less than $5 \%$ of tumor cells); $1+$ (positive signal of any intensity in $5-25 \%$ of tumor cells); $2+(26-50 \%$ of tumor cells); $3+(51-75 \%$ of tumor cells); and $4+$ (greater than $75 \%$ of tumor cells, Figure 1 ).

Statistical analysis was performed using the statistical package SPSS software (Version 22.0, SPSS Inc., Chicago, IL, USA). If continuous variables were normal, they were describle as the mean \pm standard deviation $(p>0.05$ in Kolmogorov-Smirnov test or Shapira-Wilk $(n<30))$; and if the continuous variables were not normal,

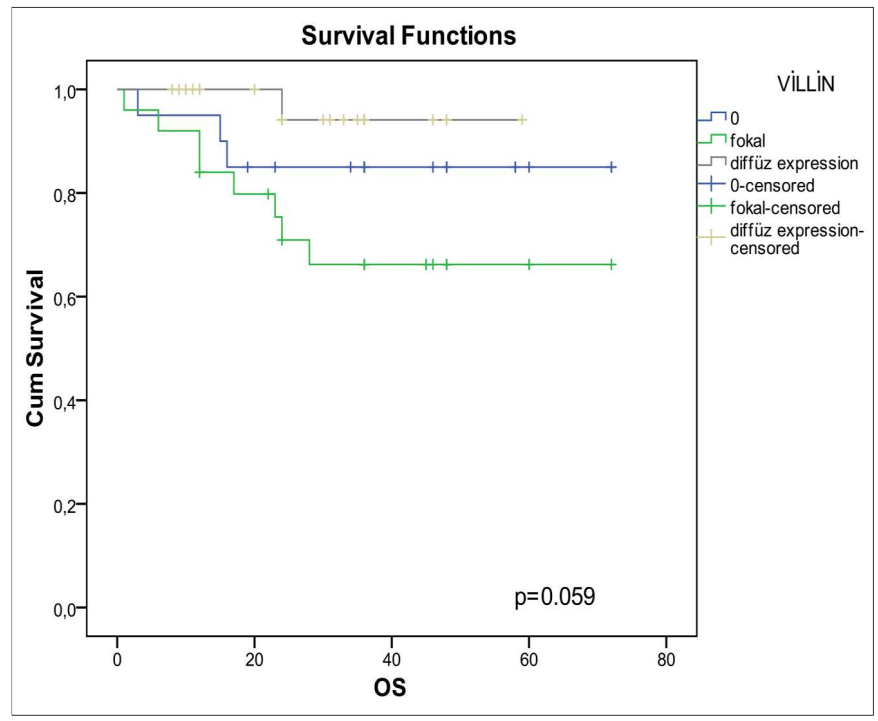

Figure 2: Villin immunoexpression and survival.

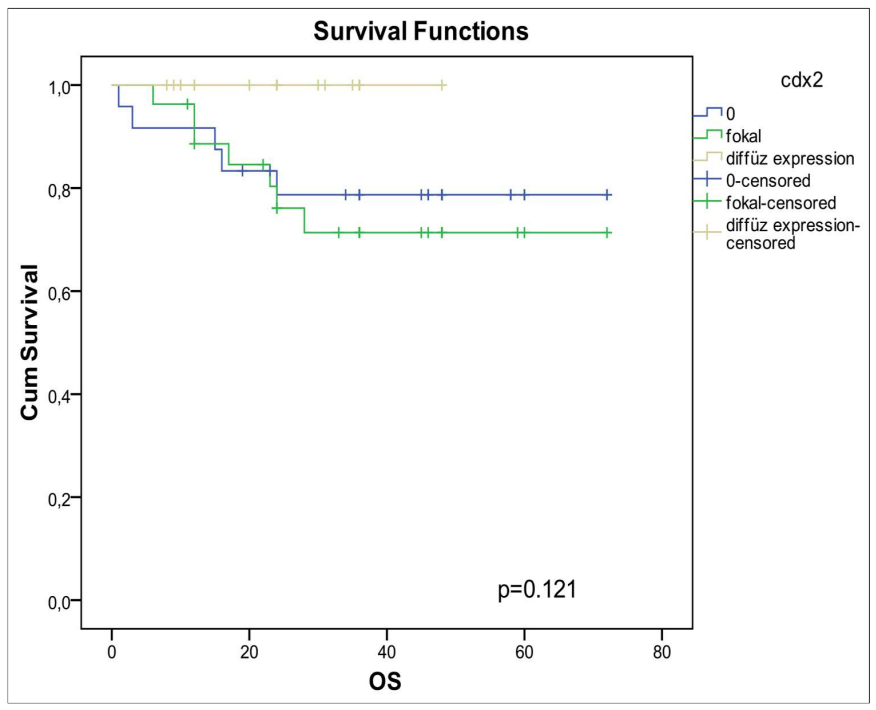

Figure 3: CDX2 immunoexpression and survival 
they were described as the median. The catagorical variables between the groups were analysed by using the Chi-square test or Fisher Exc. test. Overall survival time was defined as the years elapsed between date of after operation and death as a result of disease (or the last follow-up date). Overall survival was analysed using the Wald test, and the log-rank test was used to examine their relationship when different parameters were applied. The survival curve was plotted using the standard Kaplan-Meier methodology.

Values of $p<0.05$ were considered statistically significant.

\section{RESULTS}

The general characteristics and the distribution of the clinicopathologic data of the patients are shown in Table I. Fourty-one (58. 6\%) were men and $29(41.4 \%)$ were women; and median age was $62(29-84)$ years. There were $19(27.1 \%)$ patients of right colon carcinoma, 17 (24.3\%) patients of left colon carcinoma, and 34 (48.6\%) cases of rectal cancer. The mean size of the tumor was $6.0 \pm 2.0 \mathrm{~cm}$ ranging from 3.0 to $12.0 \mathrm{~cm}$.

The pathologic tumor classification found well differentiated adenocarcinoma in 13 patients (18.6\%), moderately differentiated adenocarcinoma in 53 cases $(75.7 \%)$, and poorly differentiated adenocarcinoma in four cases $(5.7 \%)$.

Table I: General characteristics of the study population.

\begin{tabular}{|c|c|c|}
\hline & $\mathrm{n}$ & $\%$ \\
\hline \multicolumn{3}{|l|}{ Age } \\
\hline$\leq 60$ & 31 & 44.3 \\
\hline$>60$ & 39 & 55.7 \\
\hline \multicolumn{3}{|l|}{ Sex } \\
\hline Male & 41 & 58.6 \\
\hline Female & 29 & 17.1 \\
\hline \multicolumn{3}{|l|}{ Status } \\
\hline Alive & 58 & 82.9 \\
\hline Dead & 12 & 17.1 \\
\hline \multicolumn{3}{|l|}{ Site of tumor } \\
\hline Right colon & 19 & 27.1 \\
\hline Left colon & 17 & 24.3 \\
\hline Rectum & 34 & 48.6 \\
\hline \multicolumn{3}{|l|}{ Histologic grade } \\
\hline Well differentiated adenocarcinoma & 13 & 18.6 \\
\hline Moderately differentiated adenocarcinoma & 53 & 75.7 \\
\hline Poorly differentiated adenocarcinoma & 4 & 5.7 \\
\hline \multicolumn{3}{|l|}{ Nodal status (pathological) } \\
\hline No & 34 & 48.6 \\
\hline N1 & 23 & 32.9 \\
\hline N2 & 13 & 18.6 \\
\hline \multicolumn{3}{|l|}{ TNM stage } \\
\hline III & 66 & 94.3 \\
\hline IV & 4 & 5.7 \\
\hline \multicolumn{3}{|l|}{ Lymphovascular invasion } \\
\hline Negative & 31 & 44.3 \\
\hline Positive & 39 & 55.7 \\
\hline \multicolumn{3}{|l|}{ Perineural invasion } \\
\hline Negative & 60 & 85.7 \\
\hline Positive & 10 & 14.3 \\
\hline
\end{tabular}

The pathological surgical specimen nodal classification was N0 in 34 cases $(48.6 \%), \mathrm{N} 1$ in 23 cases $(32.9 \%)$, and $\mathrm{N} 2$ in 13 cases $(18.6 \%)$. Most patients belonged to stage $3(n=66,94.3 \%)$. Four patients $(n=4,5.7 \%)$ had distant metastasis. Twelve (17.1\%) patients died at the endpoint of the study. Positive expression of CDX2 and Villin was $65.7 \%$ (46 out of 70 ), $71.4 \%$ (50 out of 70 ), respectively.

The distribution of Villin expression in colon carcinoma samples in relation to clinicopathological characteristics is shown in Table II. There was no statically important distinction with any of the clinicopathological parameters like age, location, depth of invasion, lymph node metastasis, grade, TNM stage and lymphovascular and perineural invasion. Kaplan-Meier survival analyses did not show a significant association with villin immunoexpression and survival (Figure 2).

The distribution of CDX2 expression in relation to clinicopathological characteristics is shown in Table III. Similarly, Villin there was no important relation between CDX2 expression and clinicopathological parameters.

Table II: Association between Villin expression and clinicopathological parameters of colorectal carcinoma.

\begin{tabular}{|c|c|c|c|c|c|}
\hline & \multicolumn{2}{|c|}{ Negative } & \multicolumn{2}{|c|}{ Positive } & \multirow[t]{2}{*}{$\mathrm{p}$} \\
\hline & $\mathrm{n}$ & $\%$ & $\mathrm{n}$ & $\%$ & \\
\hline \multicolumn{6}{|l|}{ Age } \\
\hline$\leq 60$ & 8 & 40.0 & 23 & 46.0 & 0.791 \\
\hline$>60$ & 12 & 60.0 & 27 & 54.0 & \\
\hline \multicolumn{6}{|l|}{ Sex } \\
\hline Male & 7 & 35.0 & 34 & 68.0 & 0.016 \\
\hline Female & 13 & 65.0 & 16 & 32.0 & \\
\hline \multicolumn{6}{|l|}{ Status } \\
\hline Alive & 17 & 85.0 & 41 & 82.00 & 1.00 \\
\hline Dead & 3 & 15.0 & 9 & 18.00 & \\
\hline \multicolumn{6}{|l|}{ Site of tumor } \\
\hline Right colon & 6 & 30.0 & 13 & 26.0 & 0.921 \\
\hline Left colon & 5 & 25.0 & 12 & 24.0 & \\
\hline Rectum & 9 & 45.0 & 25 & 50.0 & \\
\hline \multicolumn{6}{|l|}{ Histologic grade } \\
\hline $\begin{array}{l}\text { Well differentiated } \\
\text { adenocarcinoma }\end{array}$ & 3 & 15.0 & 10 & 20.0 & 0.579 \\
\hline $\begin{array}{l}\text { Moderately differentiated } \\
\text { adenocarcinoma }\end{array}$ & 15 & 75.0 & 38 & 76.0 & \\
\hline $\begin{array}{l}\text { Poorly differentiated } \\
\text { adenocarcinoma }\end{array}$ & 2 & 10.0 & 2 & 4.00 & \\
\hline \multicolumn{6}{|l|}{ Nodal status (pathological) } \\
\hline No & 8 & 40.0 & 26 & 52.0 & 0.392 \\
\hline N1 & 9 & 45.0 & 14 & 28.0 & \\
\hline N2 & 3 & 15.0 & 10 & 20.0 & \\
\hline \multicolumn{6}{|l|}{ TNM stage } \\
\hline III & 19 & 95.0 & 47 & 94.0 & 1.000 \\
\hline IV & 1 & 5.0 & 3 & 6.0 & \\
\hline \multicolumn{6}{|l|}{ Lymphovascular invasion } \\
\hline Negative & 8 & 40.0 & 47 & 94.0 & 1.000 \\
\hline Positive & 12 & 60.0 & 27 & 54.0 & \\
\hline \multicolumn{6}{|l|}{ Perineural invasion } \\
\hline Negative & 20 & 100.0 & 40 & 80.0 & 0.053 \\
\hline Positive & 0 & 0.0 & 10 & 20.0 & \\
\hline
\end{tabular}


Table III: Association between CDX2 expression and clinicopathological parameters of colorectal carcinoma.

\begin{tabular}{|c|c|c|c|c|c|}
\hline & \multicolumn{2}{|c|}{ Negative } & \multicolumn{2}{|c|}{ Positive } & \multirow[t]{2}{*}{$\mathrm{p}$} \\
\hline & $\mathrm{n}$ & $\%$ & $\mathrm{n}$ & $\%$ & \\
\hline \multicolumn{6}{|l|}{ Age } \\
\hline$\leq 60$ & 10 & 41.7 & 21 & 45.7 & 0.804 \\
\hline$>60$ & 14 & 58.3 & 25 & 54.3 & \\
\hline \multicolumn{6}{|l|}{ Sex } \\
\hline Male & 10 & 41.7 & 31 & 67.4 & 0.045 \\
\hline Female & 14 & 58.3 & 15 & 32.6 & \\
\hline \multicolumn{6}{|l|}{ Status } \\
\hline Alive & 19 & 79.2 & 39 & 84.8 & 0.739 \\
\hline Dead & 5 & 20.8 & 7 & 15.2 & \\
\hline \multicolumn{6}{|l|}{ Site of tumor } \\
\hline Right colon & 10 & 41.7 & 9 & 19.6 & 0.131 \\
\hline Left colon & 4 & 16.7 & 13 & 28.3 & \\
\hline Rectum & 10 & 41.7 & 24 & 52.2 & \\
\hline \multicolumn{6}{|l|}{ Histologic grade } \\
\hline $\begin{array}{l}\text { Well differentiated } \\
\text { adenocarcinoma }\end{array}$ & 4 & 16.7 & 9 & 19.6 & 0.209 \\
\hline $\begin{array}{l}\text { Moderately differentiated } \\
\text { adenocarcinoma }\end{array}$ & 17 & 70.8 & 36 & 78.3 & \\
\hline $\begin{array}{l}\text { Poorly differentiated } \\
\text { adenocarcinoma }\end{array}$ & 3 & 12.5 & 1 & 2.2 & \\
\hline \multicolumn{6}{|l|}{ Nodal status (pathological) } \\
\hline No & 7 & 29.2 & 27 & 58.7 & 0.603 \\
\hline $\mathrm{N} 1$ & 11 & 48.8 & 12 & 26.1 & \\
\hline N2 & 6 & 25.0 & 7 & 15.2 & \\
\hline \multicolumn{6}{|l|}{ TNM stage } \\
\hline III & 22 & 91.7 & 44 & 95.7 & 0.080 \\
\hline IV & 2 & 8.3 & 2 & 4.3 & \\
\hline \multicolumn{6}{|l|}{ Lymphovascular invasion } \\
\hline Negative & 7 & 29.2 & 24 & 52.2 & \\
\hline Positive & 17 & 70.8 & 22 & 47.8 & \\
\hline \multicolumn{6}{|l|}{ Perineural invasion } \\
\hline Negative & 22 & 91.7 & 38 & 82.6 & 0.476 \\
\hline Positive & 2 & 8.3 & 8 & 17.4 & \\
\hline
\end{tabular}

The Kaplan-Meier survival analyses did not show a significant association between CDX2 immunoexpression and survival (Figure 3).

\section{DISCUSSION}

Because of the heterogeneity of the disease outcome, it is much more important to understand the molecular pathology underlying $\mathrm{CRC}$ to discover more prognostic molecules and finally to improve therapeutic interventions. It has been suggested that it controls numerous genes that are involved in multiple procedures such as proliferation, migration, cell adhesion and tumorigenesis. ${ }^{10}$ It is used as a prognostic factor in gastric cancer; but its prognostic significance in colorectal cancer remains contro-versial. 11,12

Preceding researches have conducted a broad difference in the ratio of CRCs that express CDX2.13,14 Kaimaktchiev et al. determined CDX2 expression in $86 \%$ of CRC and he found an inverse correlation with stage and grade. 9 In a meta-analysis of 9 studies, Yu et al. showed that low expression of CDX2 was relevant to a poor outcome in colorectal cancer.2 Baba et al. 15 had found that CDX2 loss was independently related with female gender, high tumor grade, and advanced tumor. In their study, CDX2 loss was independently related with poor outcome among patients with a family history of colorectal carcinoma. However, it was not in those with no family history. Matsuda et al. conducted CDX2 expression in $80 \%$ of $C R C$ and he found an inverse correlation with survival. 16 Lugli et al. found that loss of CDX2 expression associated with MMR deficiency, ${ }^{14}$ but not outcome. Zheng et al. found CDX2 expression in $80 \%$ of CRC, and he showed that CDX2 inversely related with grade and stage. 17 Bauer et al. showed that CDX2 expression conversely related to poor prognosis in right-sided cancers. ${ }^{18}$

CDX2 was found to be expressed in $65.7 \%$ of cases. There was no statistically important correlation between CDX2 expression and patients' age, tumour location, depth of invasion, grade, metastasis of lymph node, lymphovascular and perineural invasion. Survival analysis also did not show a significant association with immunoexpression of CDX2.

In the presently studied tumour samples, Villin was found to be expressed in $71.4 \%$ of cases. However, like CDX2 there was no statistically important correlation between Villin expression and patients' age, tumour location, depth of invasion, grade, metastasis of lymph node, lymphovascular and perineural invasion. Survival analysis did not show a significant relation with immunoexpression of Villin. Similarly, Arango et al. found no such association between Villin staining intensity and overall prognosis in CRC. ${ }^{19}$ However, in a study by Al-Maghrabi et al., Villin immunoexpression in CRC was related with better survival, well-differentiated cancers, and small-sized cancers. ${ }^{8}$

The most important finding in this study is the close correlation of CDX2 and Villin ( $r=0.76, p=0.0001)$. Literature could not be found about any study about the correlation of these molecules in CRC. Yamamichi et al. conducted a relation between expression of the highly correlated CDX2 transcription factor and Villin expression in a study of gastric cancer. ${ }^{20}$ They concluded that CDX2 regulates the expression of intestinal villus by collecting the Brm-type SWI / SNF complex into the Villin promoter. ${ }^{20}$

\section{CONCLUSION}

CDX2 and Villin were not associated with any of the clinicopathologic parameters like age, sex, location, grade, metastasis of lymph node, lymphovascular and perineural invasion. Survival analysis also did not show a significant association with immunoexpression of these molecules. Our findings proposed that CDX2 and Villin might not be useful as a prognostic factor in advanced stage colorectal carcinoma. More in vivo and in vitro researches are needed for further clarification of how these two molecules might have a relation in tumorigenesis of CRC. 


\section{ETHICAL APPROVAL:}

Cukurova University Clinical Ethical Board approved this study and ethical approvals were obtained prior to initiation of the research work.

\section{PATIENTS' CONSENT:}

Informed consents were obtained from the patients to publish the data concerning this case.

\section{CONFLICT OF INTEREST:}

Authors declared no conflict of interest.

\section{AUTHORS' CONTRIBUTION:}

SA: Conducted immunohistogical and pathogical examinations and interpreted the patients' data regarding advanced stage colorectal disease.

MB: Performed the operations and interpreted the patients' data regarding advanced stage colorectal disease.

YA: Analysed and interpreted the patients' data regarding advanced stage colorectal and was a major contributor in writing the manuscript.

\section{REFERENCES}

1. Nozoe T, Kohno M, Iguchi T, Maeda T, Ezaki T. Five-point scoring system based on clinicopathological data: A convenient criterion to determine prognosis of patients with colorectal carcinoma. Oncol Lett 2013; 5:978-82.

2. Hongbin Yu, Heng Zhang, Qixin Cao, Wei Zhu. The prognostic value of CDX2 in colorectal cancer: A meta-analysis. Int J Clin Exp Med 2016; 9:15955-60.

3. Drummond F, Putt W, Fox M, Edwards YH. Cloning and chromosome assignment of the human CDX2 gene. Ann Hum Genet 1997; 61(Pt 5):393-400.

4. Soubeyran P, Mallo GV, Moucadel V, Dagorn JC and lovanna JL. Overexpression of CDX1 and CDX2 homeogenes enhances expression of the HLA-I in HT-29 cells. Mol Cell Biol Res Commun 2000; 3:271-6.

5. Mallo GV, Soubeyran P, Lissitzky JC, Andre F, Farnarier C. Expression of the CDX1 and CDX2 homeotic genes leads to reduced malignancy in colon cancer-derived cells. J Biol Chem 1998; 273:14030-6.

6. Athman R, Louvard D, Robine S. The epithelial cell cytoskeleton and intracellular trafficking III. How is villin involved in the actin cytoskeleton dynamics in intestinal cells? Am J Physiol 2002; 283:G496-G502.

7. Moll R, Robine S, Dudouet B, Louvard D. Villin: a cytoskeletal protein and a differentiation marker expressed in some human adenocarcinomas. Virchows Arch B 1987; 54:155-69.
8. Al-Maghrabi J, Gomaa W, Buhmeida A, Al-Qahtani M, Al-Ahwal M. Loss of villin immunoexpression in colorectal carcinoma is associated with poor differentiation and survival. ISRN Gastroenterol 2013; 2013:679724.

9. International Union Against Cancer (2009) TNM classification of malignant tumours, $7^{\text {th }}$ ed. Wiley-Blackwell, West-Sussex.

10. Coskun M, Troelsen JT, Nielsen $\mathrm{OH}$. The role of CDX2 in intestinal homeostasis and inflammation. Biochim Biophys Acta 2011; 1812:283-9.

11. Xiao ZY, Ru Y, Sun JT, Gao SG, Wang YF, Wang LD, et al. Expression of CDX2 and villin in gastric cardiac intestinal metaplasia and the relation with gastric cardiac carcinogenesis. Asian Pac J Cancer Prev 2012; 13:247-50.

12. Wang XT, Wei WY, Kong FB, Lian C, Luo W, Xiao Q, et al. Prognostic significance of $\mathrm{CDX} 2$ immunohistochemical expression in gastric cancer: A meta-analysis of published literatures. J Exp Clin Cancer Res 2012; 31:98.

13. Kaimaktchiev V, Terracciano L, Tornillo L, Spichtin H, Stoios D, Bundi $\mathrm{M}$, et al. The homeobox intestinal differentiation factor CDX2 is selectively expressed in gastrointestinal adenocarcinomas. Mod Pathol 2004; 17:1392-9.

14. Lugli A, Tzankov A, Zlobec I, Terracciano LM. Differential diagnostic and functional role of the multi-marker phenotype CDX2/CK20/CK7 in colorectal cancer stratified by mismatch repair status. Mod Pathol 2008; 21:1403-12.

15. Baba Y, Nosho K, Shima K, Freed E, Irahara N, Philips J, et al. Relationship of CDX2 loss with molecular features and prognosis in colorectal cancer. Clin Cancer Res 2009; 15 : 4665-73.

16. Matsuda M, Sentani $K$, Noguchi $T$, Hinoi T, Okajima $M$, Matsusaki $\mathrm{K}$, et al. Immunohistochemical analysis of colorectal cancer with gastric phenotype: Claudin-18 is associated with poor prognosis. Pathol Int 2010; 60:673-80.

17. Zheng LD, Tong QS, Weng MX, He J, Lv Q, Pu JR, et al. Enhanced expression of resistin-like molecule beta in human colon cancer and its clinical significance. Dig Dis Sci 2009; 54: 274-81.

18. Bauer KM, Hummon AB, Buechler S. Right-side and left-side colon cancer follow different pathways to relapse. Mol Carcinog 2012; 51:411-21.

19. Arango D, Al-Obaidi S, Williams DS, Dopeso $H$, Mazzolini R, Corner $\mathrm{G}$, et al. Villin expression is frequently lost in poorly differentiated colon cancer. Am J Pathol 2012; 180:1509-21.

20. Yamamichi N, Inada K, Furukawa C, Sakurai K, Tando T, Ishizaka A, et al. CDX2 and the Brm-type SWI/SNF complex cooperatively regulate villin expression in gastrointestinal cells. Exp Cell Res 2009; 315:1779-89. 